\title{
Operative Morbidity and Mortality of Left Ventricular Surgical Retraining in Patients with Transposition of the Great Arteries and Loss of Ventricular Mass
}

\author{
Osbaldo Espinosa Blanco, Edgar Samuel Ramírez Marroquín, Juan E Calderon-Colmenero, Marlo D Paul Ortiz Vazquez, and \\ Jorge Luis Cervantes Salazar*
}

Department of Pediatric Cardiac Surgery and Congenital Heart Disease, National Institute of Cardiology, Mexico

*Corresponding author: Jorge Luis Cervantes Salazar, Department of Pediatric Cardiac Surgery and Congenital Heart Disease, National Institute of Cardiology, Mexico, Email: jorgeluis.cervantes@gmail.com

Received: 17 Jan, 2021 | Accepted: 17 Jun, 2021 | Published: 08 Jul, 2021

Citation: Blanco OE, Marroquín ESR, Calderon-Colmenero JE, Vazquez MDPO, Salazar JLC (2021) Operative Morbidity and Mortality of Left Ventricular Surgical Retraining in Patients with Transposition of the Great Arteries and Loss of Ventricular Mass. J Surg Open Access 7(3): dx.doi.org/10.16966/2470-0991.244

Copyright: (C) 2021 Blanco OE, et al. This is an open-access article distributed under the terms of the Creative Commons Attribution License, which permits unrestricted use, distribution, and reproduction in any medium, provided the original author and source are credited.

\begin{abstract}
Objective: To describe the operative morbidity and mortality of surgical retraining of the left ventricle in patients with transposition of the great arteries and loss of ventricular mass.

Method: A retrospective, cross-sectional, descriptive and observational study was performed in 28 patients with transposition of the great arteries and unprepared left ventricle who underwent a left ventricular preparation surgery by a pulmonary band and/or systemic-pulmonary fistula type Blalock-Taussig changed in 8 years.

Results: Patients who met the following criteria were included in the study: average age of 3 months, predominantly female, average weight of 3,758 grams and height of $53 \mathrm{~cm} ; 61 \%$ had transposition of the great arteries without ventricular communication, with an average left ventricular mass of $44 \mathrm{gr} / \mathrm{m}^{2}, 79 \%$ underwent preoperative atrioseptostomy, $36 \%$ were intubated before surgery, $14 \%$ had preoperative sepsis and $57 \%$ received prostaglandins, the preoperative pressure of the right ventricle, left ventricle and pulmonary were 64,46 , and $45 \mathrm{mmHg}$ respectively. Most of the patients (86\%) underwent pulmonary artery banding with systemic-pulmonary fistula and the rest only pulmonary banding. The mean pulmonary transband gradient was $48 \mathrm{mmHg}$, the stay length in the intensive care unit was 11 days, the postoperative intubation was 17 days, and the hospital stay was 24 days. The most frequent causes of morbidity were heart failure and sepsis. The leading cause of death was sepsis, followed by heart failure.
\end{abstract}

Conclusion: Left ventricular retraining surgery to treat transposition of the great arteries with loss of ventricular mass does not seem to give the expected satisfactory results because of the high morbidity and mortality and its low percentage of success in the definitive anatomical correction.

Keywords: Ventricular preparation; Transposition; Jatene; Mexico

\section{Introduction}

The classic Transposition of the Great Arteries (TGA) is a conaltrunk cardiac malformation characterized by an abnormal emergence of the aorta from the right ventricle and the pulmonary artery from the left ventricle [1].

The arterial switch repair or Jatene surgery is the operation of choice in the surgical management of TGA in newborns. However, sometimes newborns are referred late to hospital centers and by that time, the left ventricle is already involved and losing its ventricular mass. This involution is because the ability of the left ventricle to sustain systemic circulation slowly decreases after the first two weeks of life, a consequence of a loss of ventricular mass due to the decrease in pulmonary vascular resistance. Therefore, survival will depend on the permeability of the ductus arteriosus, the level of pulmonary vascular resistance, the defect size of the interatrial septum and the obstruction of the left ventricular outflow tract. In cases of TGA with loss of ventricular mass that escape a conventional treatment with an arterial switch, correction in two stages should be adopted as a therapeutic measure [1-4]. The first comprises a re-training of the left ventricle to later propose in a second stage a Jatene's surgery. The left ventricular retraining comprises a pulmonary artery banding, usually associated with a systemic-pulmonary fistula [1-11].

The evaluation of the muscle mass of the left ventricle is carried out through echocardiography using the formula of the American Society of Echocardiography, in which the mass is indexed according to the body surface area. A left ventricular mass index of $35 \mathrm{~g} / \mathrm{m}^{2}$ is the lower limit to show a left ventricular retraining in most patients. A left ventricular retraining is recommended based on a combination of different factors, but mainly due to the already exposed muscle mass index, age greater than three weeks, shape of the interventricular septum, defects of interventricular septum, persistence of the ductus arteriosus, and the obstruction of left ventricular outflow tract [2-14]. 


\section{Materials and Methods}

This is a retrospective, cross-sectional, descriptive, and observational study of patients with TGA and an unprepared left ventricle who underwent a pulmonary banding surgery and/or modified BlalockTaussig fistula at the Ignacio Chávez National Institute of Cardiology, in 8 years.

A review of all the clinical records in the institution's archive was made, and the data was collected on an evaluation sheet pre-designed for this purpose. Of all the variables considered, the following were prioritized, divided into four groups: pre-operative variables (presence of TGA with a Ventricular Septal Defect (VSD), left ventricular mass, atrioseptostomy, and use of prostaglandins), intraoperative (size of the pulmonary artery binding and systemic-pulmonary fistula diameter), immediate postoperative (trans-band echocardiographic gradient, stay length in the intensive care unit, operative morbidity and mortality), and follow-up variables (performance of anatomical correction or not with a Jatene's surgery). The information was compiled in an Excel spreadsheet for later analysis, emphasizing the operative morbidity and mortality. Operative mortality was considered during the first 30 days after the surgical treatment or upon discharge of the patient, and late mortality after this period. Morbidity comprised all the following events: sepsis, heart failure, intracerebral hemorrhage, pneumonia, supraventricular tachycardia and necrotizing enterocolitis, and a left ventricular mass index of $35 \mathrm{~g} / \mathrm{m}^{2}$ (lower limit) indicated a re-training of the left ventricular in all patients.

\section{Surgical technique}

All patients were taken to the operating room for a left ventricular retraining surgery under balanced general anesthesia. Invasive and non-invasive monitoring was previously performed by placing a central catheter with a jugular approach and placing a right or left radial arterial line. Patients with a right or left dorsal decubitus, depending on the pathway, were under antisepsis and sterile surgical drapes were placed. A total longitudinal median sternotomy was performed with thymus resection and longitudinal pericardiotomy to access the cardiovascular structures. Alternatively, in other cases a left posterolateral thoracotomy was performed, accessing the thoracic cavity through the fourth intercostal space. After administration of heparin $(50 \mathrm{IU} / \mathrm{kg})$, the left subclavian and pulmonary arteries were dissected (if the approach was by homolateral thoracotomy), or the right arteries (if the approach was by sternotomy). A modified Blalock-Taussig-type fistula was performed using a soft-walled polytetrafluoroethylene graft with 7-0 polypropylene and a diameter of 3.5 to $5 \mathrm{~mm}$ depending on the weight of the patient and continuous suture in both anastomotic mouths. After dissection and bypass of the pulmonary artery trunk, a polytetrafluoroethylene supravalvular band was placed ( 0.6 to $1 \mathrm{~mm}$ thick, $6 \mathrm{~mm}$ wide) adjusting the length according to the Albus and Trussler rule. The bandage was attached to the adventitia of the pulmonary artery with separate $5-0$ or $6-0$ polypropylene stitches. A pleural or mediastinal catheter was placed depending on the pathway and the chest wall was closed by planes. All the patients were managed in their immediate postoperative period in intensive care.

\section{Tracing}

Patient follow-ups were carried out periodically in the immediate postoperative period. After hospital discharge, an evaluation of the patients was performed on the postoperative period by the clinic with a clinical review. For suspected complications, an echocardiographic study was also used.

\section{Statistical analysis}

The data were compiled in an excel spreadsheet and processed using basic descriptive statistical techniques. Continuous variables were expressed as mean, standard deviation, and variability (minimum and maximum), as well as median and mode. Categorical variables are expressed in frequency and percentage in relation to the population at risk.

\section{Results}

Of the 37 patients evaluated, only 28 patients were included in the study since only these met the stipulated criteria, and their results are described below.

\section{Pre-operative results}

The average age at the time of surgery was three months, 16 females (57\%) with an average weight and height of the patients was 3,758 grams and $53 \mathrm{~cm}$, respectively. There were 11 patients (39\%) who had a VSD, but it was not significant due to its small size, the averaged preoperative muscle mass of the left ventricle was $44 \mathrm{~g} / \mathrm{m}^{2}$ and 22 patients (79\%) underwent an atrioseptostomy before surgery. The mean pressures of the right ventricle, left ventricle and the systolic pressure of the pulmonary artery were 64,46 , and $45 \mathrm{mmHg}$ respectively, $36 \%$ of the patients were intubated preoperatively with an average of 11 days of preoperative intubation. Prostaglandins were administered in $57 \%$ of the patients to prevent the closure of the ductus arteriosus and four patients (14\%) had preoperative sepsis that could have conditioned postoperative morbidity and mortality (Table 1).

\section{Trans-operative results}

Left ventricular surgical retraining comprised a pulmonary

Table 1: Preoperative clinical-demographic and echocardiographic results.

\begin{tabular}{|l|c|c|}
\hline \multicolumn{1}{|c|}{ Variables } & $\mathbf{n ( \% )}$ & Average \pm ED (min-max) \\
\hline Age (days) & & $111 \pm 168(9-660)$ \\
\hline Gender & $12(43 \%)$ & \\
\hline Male & $16(57 \%)$ & \\
\hline Female & & $3758 \pm 1407$ (2200-9000) \\
\hline Weight (grams) & & $53 \pm 10(45-100)$ \\
\hline Size (cm) & & \\
\hline Diagnosis & $11(39 \%)$ & \\
\hline TGA with VSD & $17(61 \%)$ & \\
\hline TGA sin VSD & & $44 \pm 7(28-56)$ \\
\hline LV mass preop (gr/m²) & $22(79 \%)$ & \\
\hline Atrioseptostomy preop & & \\
\hline Pressure RV (mmHg) preop & & $46 \pm 19$ (24-120) \\
\hline Pressure LV (mmHg) preop & & $45 \pm 13(20-70)$ \\
\hline SPAP (mmHg) preop & & \\
\hline Intubation preop & $10(36 \%)$ & \\
\hline Sepsis preop & $4(14 \%)$ & \\
\hline Prostaglandins preop & $16(57 \%)$ & \\
\hline
\end{tabular}

TGA: Transposition of the Great Arteries; VSD: Ventricular Septal Defect; LV: Left Ventricle; RV: Right Ventricle; SPAP: Systolic Pressure of the Pulmonary Artery 
band, and a modified Blalock-Taussig-type systemic-pulmonary fistula, 24 patients $(86 \%)$ underwent both procedures and $4(14 \%)$ only underwent lung banding. Likewise, the mean diameter of the pulmonary band calculated according to the Albus and Trussler rule was $25 \mathrm{~mm}$ and the diameter of the graft for the systemic-pulmonary fistula was on average $4 \mathrm{~mm}$ (Table 2). During the trans-operative there were no complications or deaths.

\section{Immediate post-operative results}

All patients underwent a control echocardiogram in the immediate postoperative period, reporting an average gradient across the pulmonary band of $48 \mathrm{mmHg}$ and an adequate permeability of the systemic-pulmonary fistula was observed. The average orotracheal intubation time was 17 days and the average stay in intensive care was 11 days; some patients were transferred to the hospitalization area, intubated, and subsequently extubated, hence the difference in the average number of days. The average length of hospital stay was 24 days (Table 3).

Post-operative morbidity occurred in 17 patients (61\%), the main cause being sepsis with $25 \%$ perhaps related to $14 \%$ of patients who already had sepsis before surgery, heart failure occupied $18 \%$ and with $4 \%$ each seizures, cerebrovascular disease, supra-ventricular tachycardia, necrotizing enterocolitis, and pneumonia (Figure 1). The operative mortality was $28 \%$, the main cause being sepsis in five patients, and the other cause was heart failure in three patients (Figure 2).

\section{Post-operative results in the medium term}

The average follow-up of the patients was three years and most of the patients are in NYHA/Ross functional class I with 32\%, $4 \%$ in class II and three patients were lost in the follow-up (Table 4).

Of the 28 patients who underwent a left ventricular retraining surgery, eight patients died, and 20 patients survived. Of the surviving patients, eight patients underwent a Jatene surgery in the same hospitalization, of which 4 survived and 4 died. Twelve patients who were discharged after the left ventricular retraining surgery, six

Table 2: Intraoperative results.

\begin{tabular}{|l|c|c|}
\hline \multicolumn{1}{|c|}{ Variables } & $\mathbf{n}(\%)$ & Average \pm ED (min-max) \\
\hline Procedure & $24(86 \%)$ & \\
\hline $\begin{array}{l}\text { Pulmonary artery } \\
\text { banding+systemic-pulmonary } \\
\text { fistula }\end{array}$ & $4(14 \%)$ & \\
\hline Pulmonary banding & $25 \pm 2(24-32)$ \\
\hline $\begin{array}{l}\text { Length of the pulmonary banding } \\
\text { (mm) }\end{array}$ & $4 \pm 0(3-5)$ \\
\hline $\begin{array}{l}\text { Size of the systemic-pulmonary } \\
\text { fistula }\end{array}$ & & \\
\hline
\end{tabular}

Table 3: Clinical-echocardiographic results in the immediate postoperative period.

\begin{tabular}{|l|c|}
\hline \multicolumn{1}{|c|}{ Variables } & Average \pm ED (min-max) \\
\hline Trans-banding gradient (mmHg) & $48 \pm 10(20-60)$ \\
\hline Length of stay in intensive care (days) & $11 \pm 10(1-35)$ \\
\hline Intubation time (days) & $17 \pm 19(0-60)$ \\
\hline Time of post operative hospital stay & $24 \pm 22(1-90)$ \\
\hline
\end{tabular}

underwent a Jatene surgery in a subsequent hospitalization, three patients died after surgery and three patients survived, and three patients were lost during the follow-up without having carried out the definitive correction and the other three patients underwent a Senning surgery, and two patients had another systemic pulmonary fistula, while they were currently alive (Figure 3 ). In summary, of the 28 patients who underwent a left ventricular retraining surgery, only 14 underwent a Jatene surgery and of the remaining 14, eight patients

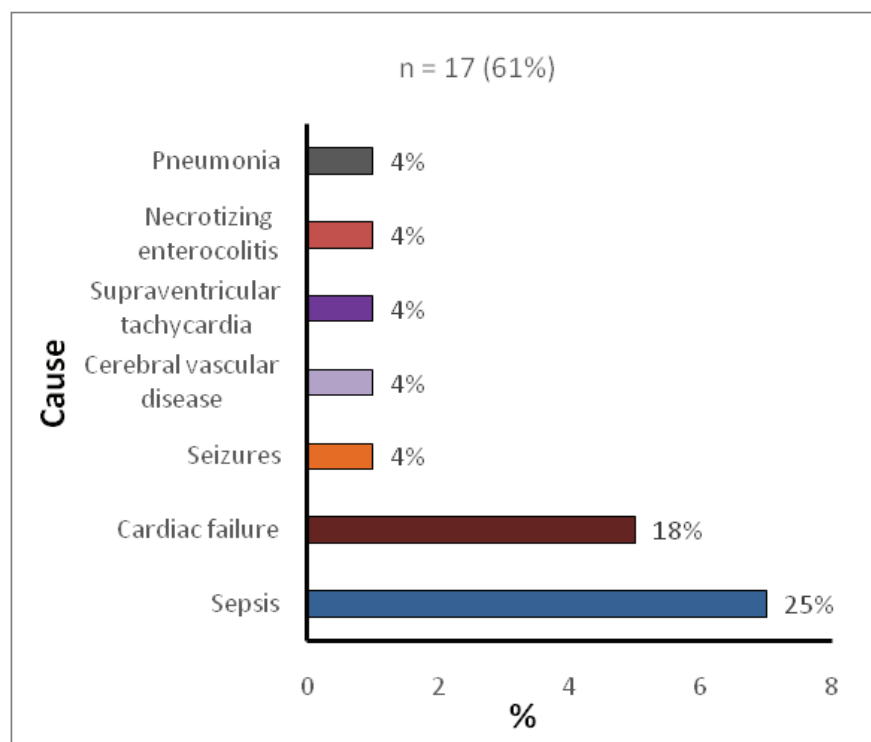

Figure 1: Causes of operative morbidity.

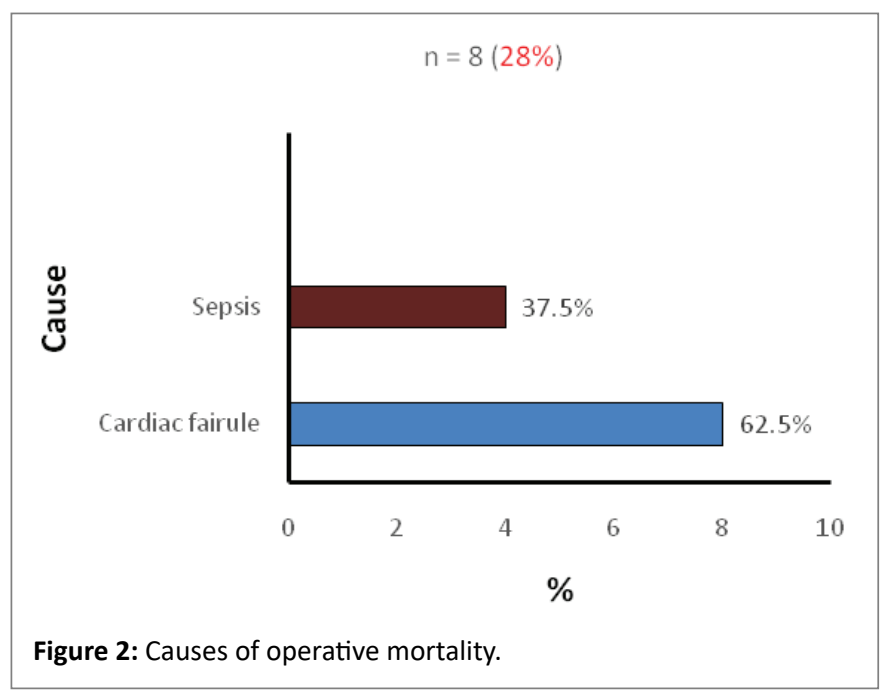

Table 4: Clinical follow-up results in the short to medium term.

\begin{tabular}{|l|c|c|}
\hline \multicolumn{1}{|c|}{ Variables } & $\mathbf{n ( \% )}$ & Average \pm ED (min-max) \\
\hline Follow up (days) & & $1107 \pm 1011$ (12-2849) \\
\hline $\begin{array}{l}\text { Functional Class-Post-op (NYHA/ } \\
\text { Ross) }\end{array}$ & & \\
\hline I & $9(32 \%)$ & \\
\hline II & $1(4 \%)$ & \\
\hline Not referred & $3(11 \%)$ & \\
\hline
\end{tabular}




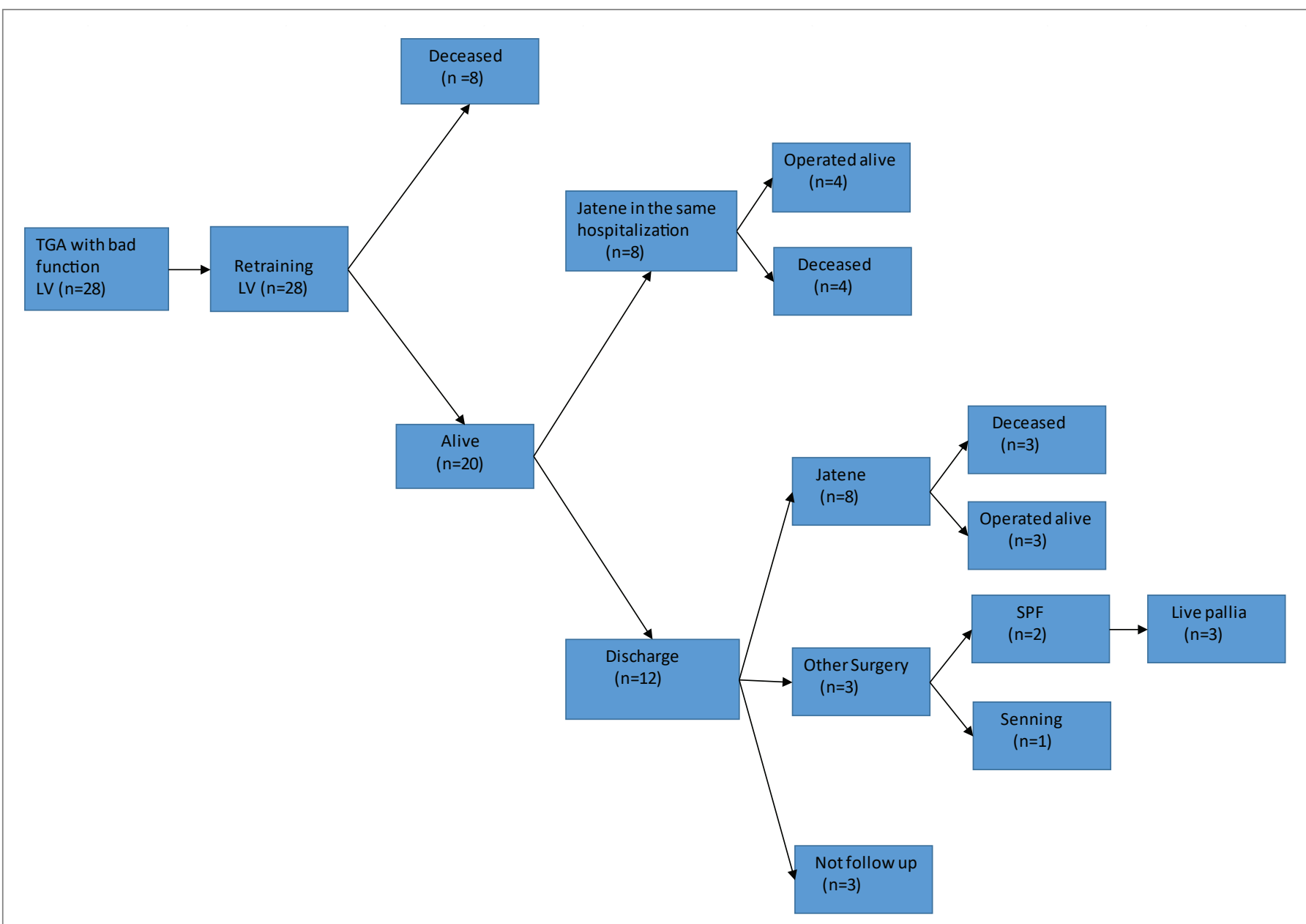

Figure 3: Total summary of the series.

TGA: Transposition of the Great Arteries; LV: Left Ventricule; SPF: Systemic-Pulmonary Fistula

died after a left ventricular retraining surgery, three were lost to followup and another three underwent a different surgery, leaving a survival of $35.7 \%$.

\section{Discussion}

\section{High mortality}

The arterial switch or Jatene surgery is the operation of choice in the surgical management of TGA in newborns. However, sometimes these patients are referred late to hospital centers and the left ventricle is involved. Our hospital is a reference center and because of this we receive patients who need a previous preparation of the left ventricle through a pulmonary banding and/or a systemic-pulmonary fistula before being able to perform Jatene's surgery [3-14]. With this management and, according to the results obtained in this study, we observed that there is a high operative mortality in preparation for surgery of the left ventricle and in the subsequent correction with Jatene's surgery, since only seven patients survived in the medium term when carrying out this approach. Therefore, it may be necessary to change how to manage patients with a left ventricle that has a borderline muscle mass with a left ventricular mass of $50-60 \mathrm{~g} / \mathrm{m}^{2}$. Mortality in the first stage can be up to $15 \%$ as described by Däbritz S, et al. [5]. In this study, we had a mortality of $28.5 \%$, which is considered a high figure. The two main death causes were sepsis and heart failure, the latter probably being related to poor preoperative ventricular function which, together with the fact that in the first days of ventricular preparation the heart suffers a transitory deterioration, it can condition the patient's death [8].

\section{Risk factors involved in high mortality}

Among the risk factors that affect mortality, a preoperative left ventricular muscle mass is one of the main ones, which is often borderline, as well as poor preoperative ventricular function [1]. In addition, some of them at the time of entering the operating room are in critical condition with several days of preoperative intubation and preoperative sepsis, which increases the risk of infection progression in the immediate postoperative period. Furthermore, sepsis was the leading cause of hospital mortality. All these factors could have influenced the high operative mortality. We had $61 \%$ morbidity comparable to the $50 \%$ reported in the Däbritz S series [5].

\section{Monitoring criticism}

We had an average follow-up of the patients of three years and a follow-up loss of $10 \%$. For a better evaluation it would have been more convenient to carry out a long-term follow-up and with this to have a better analysis of the results.

\section{Alternative solutions}

Patients who underwent a left ventricular retraining surgery and were subsequently taken for total correction either in the same 
hospitalization or later in a subsequent admission for a Jatene surgery, in the short and medium term, only seven patients survived, two ended with palliative surgery and one underwent a Senning surgery without being taken to the arterial switch. In addition, they had a high morbidity after ventricular preparation, so it is convenient to take these unsatisfactory results into account and perhaps suggest other alternative solutions such as Senning or Mustard surgery to achieve greater survival and less morbidity in patients [7-12]. Another option would also be to evaluate the ventricular function trans-operatively through a transitory pulmonary band for 15 to 30 minutes as recommended by Däbritz S, et al. [5] and to assess whether it will tolerate a Jatene surgery at that time and not take the patient to a left ventricular preparation that will lead to high morbidity and mortality. Finally, another option is that patients who at the time of the evaluation of the left ventricle are found with borderline values, a definitive anatomical correction should be performed as long as there are ventricular assist devices that may be required at the time of weaning from extracorporeal circulation or in the first hours after surgery [13].

\section{Conclusion}

A left ventricular retraining surgery to treat TGA with loss of ventricular mass, in the light of the experience in our institution, does not seem to give the expected satisfactory results due to its high morbidity and mortality and its low percentage of success in the definitive anatomical correction. Therefore, since the results of ventricular preparation are unsatisfactory, we consider that other therapeutic options should be explored, such as anatomical correction in borderline patients at the time of their evaluation, as long as there are ventricular assistance mechanisms that can be required at the time of weaning from a cardiopulmonary bypass. On the other hand, in patients who are completely out of the indication for anatomical correction and the results of ventricular preparation are unsatisfactory, physiological correction (Senning or Mustard surgery) should be considered as another option for these patients.

\section{Financial Support}

None.

\section{Conflict of Interest}

The authors declare that they have no conflict of interest.

\section{References}

1. Lacour-Gayet F, Piot D, Zoghbi J, Serraf A, Gruber P, et al. (2001) Surgical management and indication of left ventricular retraining in arterial switch for transposition of the great arteries with intact ventricular septum. Eur J Cardiothorac Surg 20: 824-829.

2. Iyer KS, Sharma R, Kumar K, Bhan A, Kothari SS, et al (1995) Serial echocardiography for decision making in rapid two-stage arterial switch operation. Ann Thorac Surg 60: 658-664.
3. Edwin F, Mamorare H, Brink J, Kinsley R (2010) Primary arterial switch operation for transposition of the great arteries with intact ventricular septum--is it safe after three weeks of age? Interact Cardiovasc Thorac Surg 11: 641-644.

4. Qethamy HOA, Aizaz K, Aboelnazar SAR, Hijab S, Faraidi YA, et al. (2002) Two-stage arterial switch operation: is late ever too late? Asian Cardiovasc Thorac Ann 10: 235-239.

5. Däbritz S, Engelhardt W, Bernuth GV, Messmer BJ (1997) Trial of pulmonary artery banding: a diagnostic criterion for 'one-stage' arterial switch in simple transposition of the great arteries beyond the neonatal period. Eur J Cardiothorac Surg 11: 112-116.

6. Bret EL, Lupoglazoff JM, Borenstein N, Fromont G, Laborde F, et al. (2005) Cardiac "fitness" training: an experimental comparative study of three methods of pulmonary artery banding for ventricular training. Ann Thorac Surg 79: 198-203.

7. Padalino MA, Stellin G, Brawn WJ, Fasoli G, Daliento L, et al. (2000) Arterial switch operation after left ventricular retraining in the adult. Ann Thorac Surg 70: 1753-1757.

8. Quinn DW, McGuirk SP, Metha C, Nightingale P, Giovanni JVD, et al. (2008) The morphologic left ventricle that requires training by means of pulmonary artery banding before the double-switch procedure for congenitally corrected transposition of the great arteries is at risk of late dysfunction. J Thorac Cardiovasc Surg 135: 1137-1144.

9. Abduch MCD, Assad RS, Rodriguez MQ, Valente AS, Andrade JL, et al. (2007) Reversible pulmonary trunk banding III: assessment of myocardial adaptive mechanisms-contribution of cell proliferation. J Thorac Cardiovasc Surg 133: 1510-1516.

10. Sun HY, Behzadian F, Punn R, Tacy TA (2013) Decremental left ventricular deformation after pulmonary artery band training and subsequent repair in ventriculoarterial discordance. J Am Soc Echocardiogr 26: 765-774.

11. Dibardino DJ, Kleeman K, Bove EL (2012) A method of transcutaneously adjustable pulmonary artery banding for staged left ventricular retraining. J Thorac Cardiovasc Surg 144: 553-556.

12. Sun HY, Behzadian F, Punn R, Tacy TA (2013) Decremental left ventricular deformation after pulmonary artery band training and subsequent repair in ventriculoarterial discordance. J Am Soc Echocardiogr 26: 765-774.

13. Boutin C, Jonas RA, Sanders SP, Wernovsky G, Mone SM, et al. (1994) Rapid two-stage arterial switch operation. Acquisition of left ventricular mass after pulmonary artery banding in infants with transposition of the great arteries. Circulation 90: 1304-0309.

14. Myers PO, Nido PJD, Geva T, Bautista-Hernandez V, Chen P, et al. (2013) Impact of age and duration of banding on left ventricular preparation before anatomic repair for congenitally corrected transposition of the great arteries. Ann Thorac Surg 96: 603-610. 